\title{
Protein-protein interactions on membrane surfaces analysed using SUPER template pull- downs
}

Devika S. Andhare and Thomas J. Pucadyil

Indian Institute of Science Education and Research, Dr. Homi Bhabha Road, Pashan, Pune 411008, Maharashtra, India

*Corresponding author: pucadyil@iiserpune.ac.in

Devika S. Andhare ORCID ID: 0000-0001-6289-4407

Thomas J. Pucadyil ORCID ID: $\underline{0000-0002-2907-9889}$

\begin{abstract}
Discovery-based proteomics workflows that identify novel interactors rely on immunoprecipitations or pull-downs with genetically-tagged bait proteins displayed on sepharose matrices. But strategies to analyse protein interactions on a diffusible membrane surface combined with the practical ease of pull-downs remain unavailable. Such strategies are important to analyse protein complexes that mature in composition and stability because of diffusion-based interactions between participant proteins. Here, we describe a generic pull-down strategy to analyse such complexes using supported membranes with excess reservoir templates displaying His-tagged bait proteins. Using clathrinmediated endocytosis as a paradigm, we find that the clathrin-binding adaptor protein epsin1 displayed as bait on these templates pulls down significantly higher amounts of clathrin from brain lysates than conventional sepharose matrices. Together, our results establish the potential of SUPER templates as superior matrices for analysing protein-protein interactions and resultant complexes formed on membrane surfaces.
\end{abstract}

\section{Keywords}

Protein-protein interactions, pulldowns, clathrin, epsin1, clathrin-mediated endocytosis, membrane

\section{Introduction}

Biochemical analyses of novel protein interactions generally rely on immunoprecipitation methods or pull-downs with genetically-tagged proteins displayed on appropriate sepharose matrices (Brymora et al. 2004; Schmidt and Skerra 2007; Pollard 2010; Lin and Lai 2017). Such strategies are however not ideal for analysing protein complexes that mature and strengthen from diffusion-controlled encounter between participant proteins. Formation of such protein complexes is apparent in several membranelocalized processes such as coated vesicular transport, formation of focal adhesion complexes and viral budding (Schmid and McMahon 2007; Shaw et al. 2008; Schumacher et al. 2021). During 
bioRxiv preprint doi: https://doi.org/10.1101/2021.12.06.471516; this version posted December 7, 2021. The copyright holder for this preprint (which was not certified by peer review) is the author/funder, who has granted bioRxiv a license to display the preprint in perpetuity. It is made available under aCC-BY-NC-ND 4.0 International license.

vesicular transport, coated bud formation is initiated by low-affinity interactions between receptors and specific lipids with their cognate adaptors, which in turn recruit coat proteins and accessory endocytic proteins. The resultant protein complexes achieve stability by high avidity interactions formed between polymerizing coat proteins (Traub 2005; Schmid and McMahon 2007; Kaksonen and Roux 2018). Previous reports describe liposome-based templates for identifying such interactors but involve tedious and elaborate strategies, both at the level of template preparation and subsequent separation of liposome-bound proteins (Zhao and Lappalainen 2012; Saliba et al. 2016; Senju et al. 2021). To circumvent these issues, we focussed on a simplified pull-down strategy using SUPER templates, which are supported membranes formed on silica beads by the fusion of negatively-charged liposomes in presence of high salt (Pucadyil and Schmid 2008; Pucadyil and Schmid 2010; Neumann et al. 2013). These templates can be sedimented at low speeds, which is a property useful in removing excess unbound proteins in reactions carried out with native tissue lysates. Here, we describe results using SUPER templates in pull-down assays, focussing on the ability of His-tagged clathrin adaptors to recruit clathrin from native tissue lysates.

\section{Materials and Methods}

\section{Protein Expression and Purification}

Human epsin 1 and its mutants cloned with an $\mathrm{N}$-terminal $6 \mathrm{xH}$ His tag and a C-terminal Strepll tag in pET15b have been described earlier (Holkar et al. 2015). mEGFP was cloned with an N-terminal $6 \mathrm{xHis}$ tag in $\mathrm{pET} 15 \mathrm{~b}$. Proteins were expressed in BL21(DE3) grown in autoinduction medium (Formedium, UK) at $18^{\circ} \mathrm{C}$ for 36 hours. Bacterial cells were pelleted and stored at $-40^{\circ} \mathrm{C}$. The frozen bacterial pellet was thawed and resuspended in $20 \mathrm{mM} \mathrm{HEPES} \mathrm{pH} \mathrm{7.4,} 150 \mathrm{mM} \mathrm{NaCl}$ (HBS) with a protease inhibitor cocktail tablet (Roche) and lysed by sonication in an ice water bath. Lysates were spun at $18,000 x \mathrm{~g}$ for 20 mins. The supernatant was incubated with HisPur ${ }^{\mathrm{TM}}$ Cobalt Resin (Thermo Fisher Scientific) for $1 \mathrm{hr}$ at $4{ }^{\circ} \mathrm{C}$ and poured into a PD-10 column. The resin was washed with $100 \mathrm{ml}$ of HBS and bound protein was eluted with HBS containing $250 \mathrm{mM}$ imidazole. For Strepll tagged constructs, elution from the HisPur ${ }^{\mathrm{TM}}$ Cobalt Resin was applied to a $5 \mathrm{ml}$ streptactin column (GE Healthcare) and washed with HBS. Proteins were eluted in HBS containing $1 \mathrm{mM}$ DTT and $2.5 \mathrm{mM}$ desthiobiotin (Sigma-Aldrich). Proteins were spun at 100,000x $\mathrm{g}$ to remove aggregates before use in assays. Protein concentration was estimated using UV absorbance at $280 \mathrm{~nm}$ based on the predicted molar extinction coefficients from the ProtParam tool in Expasy.

\section{Preparation of Brain Lysates}

Lysates from adult goat brains were prepared as described earlier (Wu et al. 2010; Kamerkar et al. 2018). Briefly, brain tissues were cleaned of meninges and blood vessels and homogenized in a Waring blender in breaking buffer ( $25 \mathrm{mM}$ Tris $\mathrm{pH}$ 8.0, $500 \mathrm{mM} \mathrm{KCl}, 250 \mathrm{mM}$ sucrose, $2 \mathrm{mM}$ EGTA, and $1 \mathrm{mM}$ DTT) with a protease inhibitor cocktail tablet (Roche). The lysate was spun at $160,000 \mathrm{xg}$ for $2 \mathrm{~h}$. The supernatant was collected and desalted on a G-50 column into $20 \mathrm{mM}$ HEPES pH 7.4 with $150 \mathrm{mM} \mathrm{KCl}$. Lysates were flash-frozen with $10 \%$ glycerol in liquid nitrogen and stored at $-80^{\circ} \mathrm{C}$. 
bioRxiv preprint doi: https://doi.org/10.1101/2021.12.06.471516; this version posted December 7, 2021. The copyright holder for this preprint (which was not certified by peer review) is the author/funder, who has granted bioRxiv a license to display the preprint in perpetuity. It is made available under aCC-BY-NC-ND 4.0 International license.

Total protein content was estimated using the Pierce BCA Protein Assay Kit (Thermo Fisher Scientific).

\section{Supported Bilayer with Excess Reservoir (SUPER) Templates}

SUPER templates were prepared as described previously (Pucadyil and Schmid 2010). All lipids were from Avanti Polar Lipids. Briefly, required aliquots of the chelating lipid 1,2-dioleoyl-sn-glycero-3-[(N(5-amino-1-carboxypentyl)iminodiacetic acid)succinyl] (nickel salt) (NTA lipid; 5 mol\%) with or without 1,2-dioleoyl-sn-glycero-3-phospho-L-serine (sodium salt) (DOPS, $15 \mathrm{~mol} \%$ ) and 1,2-dioleoyl-snglycero-3-phosphocholine (DOPC) were mixed in a clean glass tube and dried under high vacuum. Lipids were hydrated with de-ionized water to achieve a final concentration of $1 \mathrm{mM}$. The hydrated lipid suspension was probe sonicated in an ice-water bath and spun at $100,000 \mathrm{xg}$ at $25^{\circ} \mathrm{C}$ for 20 min. The supernatant containing small unilamellar vesicles (SUVs) was collected and stored at $4{ }^{\circ} \mathrm{C}$. To prepare SUPER templates, $10 \mu$ of plain silica beads ( $5.3 \mu \mathrm{m}$ diameter, Corpuscular Inc., cat. no.: 140226-10) was added to a premixed solution of $200 \mu \mathrm{M}$ SUVs and $1 \mathrm{M} \mathrm{NaCl}$ in a $1.5 \mathrm{ml}$ siliconized low-binding polypropylene tube (Star Labs, cat. no.: E1415-2600) and left with intermittent shaking for $30 \mathrm{~min}$. SUPER templates formed on the silica beads were then washed 3 times by adding $1 \mathrm{ml}$ of deionized water and pelleting at low speed $(300 \mathrm{x} \mathrm{g})$ for $2 \mathrm{~min}$ in a swinging bucket rotor. $100 \mu$ l of water was left behind after each spin to prevent drying of templates. The excess membrane reservoir in the templates was checked by adding a small aliquot of the templates to a drop of HBS on a piranhacleaned glass coverslip.

\section{SUPER Template Stability}

Template stability was assayed by monitoring the release of membrane reservoir. For this, liposomes contained an additional ( $1 \mathrm{~mol} \%$ ) of Texas Red-DHPE (Invitrogen). Briefly, $10 \mu \mathrm{l}$ of templates was added to $90 \mu \mathrm{l}$ of HBS containing increasing protein concentrations of brain lysate in $1.5 \mathrm{ml}$ polypropylene centrifuge tubes. In a separate reaction, to estimate the total lipid concentration, $10 \mu \mathrm{l}$ of templates was added to HBS containing $0.1 \%$ Triton X-100. Samples were left undisturbed for 30 $\mathrm{min}$ at room temperature and the beads were spun at $300 \mathrm{xg}$ for $2 \mathrm{~min}$ at room temperature. To estimate released membrane, $75 \mu \mathrm{l}$ of the supernatant was mixed with $25 \mu \mathrm{l}$ of $0.4 \%$ Triton X-100 and added to a 96-well plate. To estimate total membrane, $100 \mu \mathrm{l}$ of the supernatant from templates in $0.1 \%$ Triton X-100 was aliquoted into a 96 well plate. Samples were read for Texas Red fluorescence on a plate reader (Tecan Infinite M200 Pro).

\section{SUPER Template Pull-downs}

SUPER templates were incubated with $1 \mu \mathrm{M}$ of purified bait proteins in a total volume of $500 \mu \mathrm{l}$ of HBS for 30 mins at room temperature with gentle agitation and washed 3 times with $1 \mathrm{ml}$ of HBS, making sure to always leave behind $100 \mu$ of buffer. For pull-downs, templates displaying the desired bait were incubated with $500 \mu \mathrm{l}$ of $1 \mathrm{mg} / \mathrm{ml}$ brain lysate. Templates were washed 3 times with $1 \mathrm{ml}$ of HBS, making sure to leave behind $100 \mu \mathrm{l}$ of buffer. After the last wash, beads were boiled in $1 \mathrm{x}$ Laemmli's buffer and bound proteins were resolved on 10\% SDS-PAGE. 


\section{Western Blotting}

Proteins were transferred onto PVDF membrane and blocked with 5\% skimmed milk in TBST for $1 \mathrm{hr}$ at room temperature. Anti-clathrin heavy chain (TD1, Abcam, cat. no.: Ab24578) was used at a dilution recommended by the manufacturer in blocking buffer. The membrane was incubated with the primary antibody in blocking buffer for $3 \mathrm{hrs}$ at room temperature. Subsequently, the membrane was washed with TBST and incubated with suitable HRP-conjugated secondary antibody diluted in blocking buffer for $1 \mathrm{hr}$ at room temperature. Blot were rinsed with TBST and developed with chemiluminescent substrate (WestPico, Thermo Fisher Scientific) and imaged on a G:Box (Syngene).

\section{Fluorescence Imaging}

Fluorescence imaging was carried using an Olympus IX83 inverted microscope equipped with a 100X, 1.4 NA oil-immersion objective. Fluorescent probes were excited with a stable LED light source (CoolLED) and fluorescence emission was collected through appropriate filters on an Evolve 512 EMCCD camera (Photometrics). Image acquisition was controlled by Micro-Manager and rendered using ImageJ.

\section{Results and Discussion}

SUPER templates are supported membranes with excess reservoir that are formed by the binding and fusion of anionic liposomes on silica beads (Pucadyil and Schmid 2010). They are formed by saltinduced increase in binding of liposomes to the silica surface before their fusion and contain membrane reservoir in excess of what is needed to cover the bead surface.

A

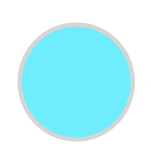

Silica bead<smiles>Oc1ccc(O)cc1</smiles>

NTA lipidcontaining

C

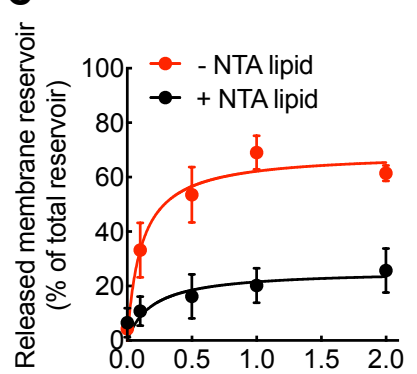

Brain lysate $(\mathrm{mg} / \mathrm{ml}$ of protein)
B

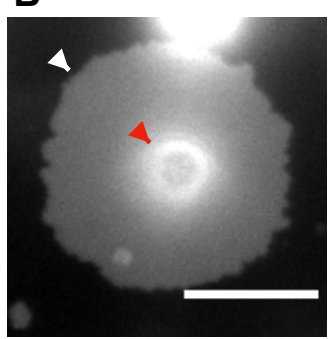

Fig. 1. Formation and stability of SUPER templates. (A) Schematic showing the process leading to the formation of SUPER templates. (B) Representative micrograph showing spillage of the excess membrane reservoir (white arrowhead) around a SUPER template (red arrowhead) on a glass coverslip. Scale bar $=10 \mu \mathrm{m}$. 
bioRxiv preprint doi: https:/doi.org/10.1101/2021.12.06.471516; this version posted December 7, 2021. The copyright holder for this preprint (which was not certified by peer review) is the author/funder, who has granted bioRxiv a license to display the preprint in perpetuity. It is made available under aCC-BY-NC-ND 4.0 International license.

(C) Stability of templates with and without NTA lipid in brain lysate analysed by estimating the release of fluorescently-labelled membrane. Data represent the mean \pm SD of 3 independent experiments.

Anionic lipids are necessary for the excess reservoir and also contributes to the stability of SUPER templates. For the purpose of developing stable membrane matrices that can display His-tagged bait proteins, we first formed templates with liposomes containing the anionic chelator lipid 1,2-dioleoyl-snglycero-3-[(N-(5-amino-1-carboxypentyl)iminodiacetic acid)succinyl] (nickel salt) (NTA lipid; 5 mol\%) with the rest being dioleoylphosphatidylcholine (DOPC) on silica beads under high salt conditions (Fig. 1A). For imaging and testing for potential vesiculation of the membrane, liposomes contained trace amounts ( $1 \mathrm{~mol} \%$ ) of a fluorescent lipid Texas Red-DHPE. Excess unbound liposomes and salt were removed by washing the templates by sedimentation at low speed $(300 \mathrm{xg})$ and resuspension. When added onto a glass coverslip, these templates bind and spill their excess reservoir, which can be seen as a membrane patch (Fig. 1B, white arrowhead) around the silica bead (Fig. 1B, red arrowhead). We then tested template stability in presence of native tissue lysates. Templates were incubated with increasing concentrations of brain lysate for 30 min with intermittent mixing followed by sedimentation at low speed $(300 \mathrm{xg})$. The supernatant was then collected and checked for released vesicles by monitoring Texas Red-DHPE fluorescence. As seen in Fig. 1C, templates with the NTA lipid were quite stable with only $20 \%$ of the total membrane undergoing vesiculation at the highest concentration of lysate tested. In contrast, templates without the NTA lipid released $60 \%$ of their membrane reservoir. Thus, inclusion of the anionic NTA lipid, which would serve to display His-tagged baits, imparts stability to the templates. To prevent potential instability arising from shielding of the anionic charge on the NTA lipid upon binding to His-tagged baits, we included dioleoylphosphatidylserine (DOPS; $15 \mathrm{~mol} \%$ ) in the templates. For convenience, we hereafter refer to these as SUPER templates.

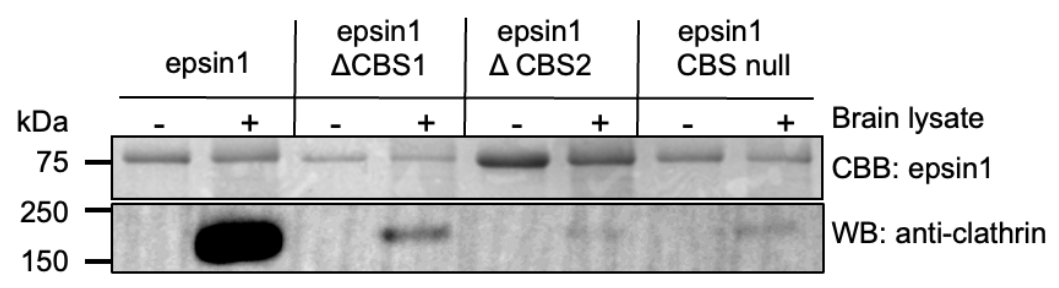

Fig. 2. SUPER template pull-downs with epsin1 as bait. Representative results of pull-downs from brain lysates using SUPER templates displaying purified epsin1 and its mutants lacking clathrin-binding sites (CBS). Coomassie Brilliant Blue (CBB)-staining shows bait proteins and Western Blot (WB) was performed using an anticlathrin antibody.

Next, we tested if SUPER templates displaying 6xHis-tagged bait proteins can pull-down known interactors from native tissue lysates. Monomeric clathrin adaptors or clathrin-associated sorting proteins (CLASPs) contain an N-terminal structured domain that binds phosphoinositide lipids and sorting motifs on cargo receptors and a C-terminal unstructured region that displays multiple short linear motifs that engage with the adaptor protein 2 (AP2), endocytic accessory proteins and clathrin 
bioRxiv preprint doi: https://doi.org/10.1101/2021.12.06.471516; this version posted December 7, 2021. The copyright holder for this preprint (which was not certified by peer review) is the author/funder, who has granted bioRxiv a license to display the preprint in perpetuity. It is made available under aCC-BY-NC-ND 4.0 International license.

(Traub 2009). We focussed on the monomeric clathrin adaptor epsin 1 because of its wellcharacterised ability to pull down clathrin from brain lysates (Drake et al. 2000). SUPER templates were first incubated with purified 6xHis-tagged epsin1. Excess protein was washed off by sedimentation and resuspension. Templates were then incubated with brain lysate $(1 \mathrm{mg} / \mathrm{ml})$ for 30 min, washed with buffer by sedimentation and resuspension and the bound proteins were resolved using SDS-PAGE. Coomassie brilliant blue (CBB) staining revealed that the templates retained epsin1 in presence of cytosol while western blots (WB) using an anti-clathrin antibody revealed efficient pulldown of clathrin (Fig. 2). Templates displaying epsin1 mutants deleted in either one or both of its clathrin-binding sites (CBS) (Holkar et al. 2015) showed severely diminished or negligible pull-down of clathrin indicating that the epsin1-clathrin interaction was specific.

A HisPur ${ }^{\mathrm{TM}}$ Cobalt Resin
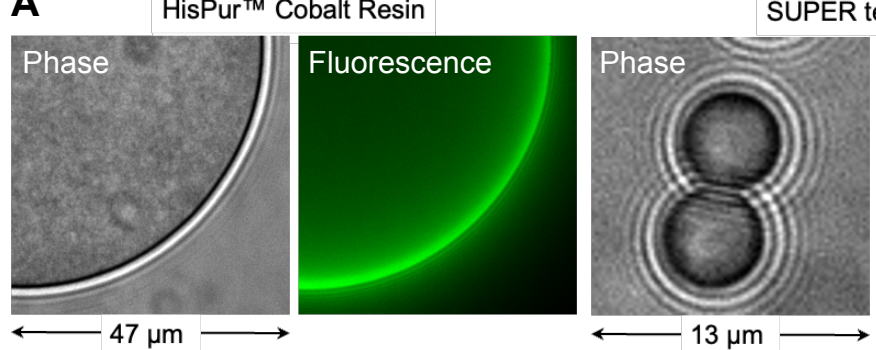

SUPER templates

B

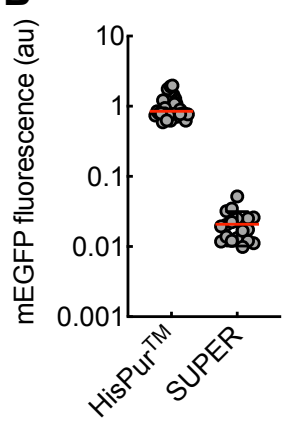

C
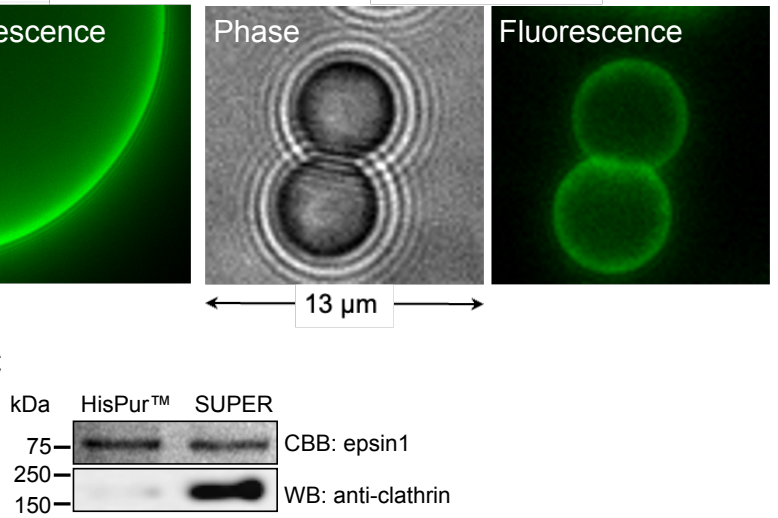

Fig. 3. Comparison between SUPER templates and sepharose matrices in pull-downs. (A) Representative phase contrast and fluorescence images of 6 XHis-mEGFP bound to HisPur ${ }^{\mathrm{TM}}$ Cobalt Resin and SUPER templates. (B) Quantitation of fluorescence of 6xHis-mEGFP bound to HisPur ${ }^{\mathrm{TM}}$ resin and SUPER templates. Each point represents data from an individual template. (C) Representative results of pull-downs from brain lysates using epsin1-coated HisPur ${ }^{\top M}$ Cobalt Resin and SUPER templates. Coomassie Brilliant Blue (CBB)staining shows the bait epsin1 and Western Blot (WB) was performed using an anti-clathrin antibody.

In comparison to previous reports showing clathrin pull-down using epsin1-coated sepharose beads (Drake et al. 2000), epsin1-displayed on SUPER templates appeared to recruit more clathrin for the amount of bait displayed on them. We tested if this was indeed the case by comparing the efficiency of clathrin pull-down with epsin1 displayed on SUPER templates and sepharose beads (HisPur ${ }^{\mathrm{TM}}$ Cobalt Resin). We first estimated the available NTA binding sites by incubating the sepharose beads and SUPER templates with saturating concentrations of 6xHis-mEGFP, followed by washing and measuring GFP fluorescence associated with the sepharose beads and SUPER templates. Such analysis revealed that HisPur ${ }^{\mathrm{TM}}$ Cobalt Resins displays 50 -fold higher NTA-binding sites than SUPER 
templates (Fig. 3A,B). So we titrated the amount of epsin1-saturated HisPur ${ }^{\top M}$ Cobalt Resins to match the concentration of epsin1 on SUPER templates and carried out clathrin pull-downs from brain Iysates. Under conditions of equivalent amounts of epsin1 in pull-downs (see CBB staining of epsin1 in Fig. 3C), epsin1 displayed on SUPER templates recruited significantly higher amounts of clathrin than when displayed on HisPurTM Cobalt Resin (Fig. 3C). Previous reports of clathrin binding to purified adaptors have revealed that low-membrane tension and a pre-curved surface significantly facilitate clathrin binding and self-assembly to membrane-bound adaptors (Dannhauser et al. 2015; Saleem et al. 2015). Self-assembly would require diffusion of adaptors on the membrane and it is possible that better performance of SUPER templates over HisPur ${ }^{\mathrm{TM}}$ Cobalt Resin could reflect these facilitatory effects on clathrin self-assembly.

In sum, we describe here a novel pull down template that would benefit analysis of proteinprotein interactions and the resultant complexes formed on membrane surfaces. While convenient, an obvious limitation of SUPER templates is the inability to incorporate transmembrane domaincontaining membrane proteins. This restricts their use to analysing interactions between peripherallyassociated membrane and soluble proteins. But a way around this limitation would be to display specific domains or motifs present on transmembrane domain-containing proteins on the template using His-tags. That aside, our results establish the versatility of SUPER templates in pull-downs since they are; (a) amenable to analysing interactions of any bait with a His-tag, (b) stable in complex mixtures of proteins such as native tissue lysates, (c) can be readily sedimented for the recovery and subsequent analysis of protein interactomes, and (d) can be further functionalized by incorporating desired lipids in the membrane.

\section{Acknowledgements}

We thank Apoorva Bhapkar for testing stability of SUPER templates with brain lysates and Rashim Malhotra and Somya Madan for initial results on pull downs with SUPER templates. We thank Pucadyil Lab members for valuable comments on the manuscript.

\section{Author Contributions}

The study was conceptualized by DSA and TJP. Experiments were performed by DSA. Data analysis and manuscript preparation was carried out by DSA and TJP.

\section{Funding}

DSA thanks the University Grants Commission (UGC) for a graduate research fellowship. TJP is an International Research Scholar of the Howard Hughes Medical Institute (HHMI) and thanks the HHMI for funding support.

\section{Declarations}

Conflict of interest: The authors declare no conflict of interest.

\section{References}


bioRxiv preprint doi: https://doi.org/10.1101/2021.12.06.471516; this version posted December 7,2021 . The copyright holder for this preprint (which was not certified by peer review) is the author/funder, who has granted bioRxiv a license to display the preprint in perpetuity. It is made available under aCC-BY-NC-ND 4.0 International license.

Brymora A, Valova VA, Robinson PJ (2004) Protein-protein interactions identified by pull-down experiments and mass spectrometry. Curr Protoc Cell Biology 22:17.5.1-17.5.51. https://doi.org/10.1002/0471143030.cb1705s22

Dannhauser PN, Platen M, Böning H, Ungewickell H, Schaap IAT, Ungewickell EJ (2015) Effect of clathrin light chains on the stiffness of clathrin lattices and membrane budding: properties of clathrin on solid and soft surfaces. Traffic 16:519-533. https://doi.org/10.1111/tra.12263

Drake MT, Downs MA, Traub LM (2000) Epsin binds to clathrin by associating directly with the clathrin-terminal domain: evidence for cooperative binding through two discreet sites. J Biol Chem 275:6479-6489. https://doi.org/10.1074/jbc.275.9.6479

Holkar SS, Kamerkar SC, Pucadyil TJ (2015) Spatial control of epsin-induced clathrin assembly by membrane curvature. J Biol Chem 290:14267-14276. https://doi.org/10.1074/jbc.m115.653394

Kaksonen M, Roux A (2018) Mechanisms of clathrin-mediated endocytosis. Nat Rev Mol Cell Bio 19:313-326. https://doi.org/10.1038/nrm.2017.132

Kamerkar SC, Roy K, Bhattacharyya S, Pucadyil TJ (2018) A screen for membrane fission catalysts identifies the ATPase EHD1. Biochemistry 58:65-71. https://doi.org/10.1021/acs.biochem.8b00925

Lin J-S, Lai E-M (2017) Bacterial protein secretion systems, methods and protocols. Methods Mol Biol 1615:211219. https://doi.org/10.1007/978-1-4939-7033-9_17

Neumann S, Pucadyil TJ, Schmid SL (2013) Analyzing membrane remodeling and fission using supported bilayers with excess membrane reservoir. Nat Protoc 8:213-222. https://doi.org/10.1038/nprot.2012.152

Pollard TD (2010) A guide to simple and informative binding assays. Mol Biol Cell 21:4061-4067. https://doi.org/10.1091/mbc.e10-08-0683

Pucadyil TJ, Schmid SL (2010) Supported bilayers with excess membrane reservoir: a template for reconstituting membrane budding and fission. Biophys J 99:517-525. https://doi.org/10.1016/j.bpj.2010.04.036

Pucadyil TJ, Schmid SL (2008) Real-time visualization of dynamin-catalyzed membrane fission and vesicle release. Cell 135:1263-1275. https://doi.org/10.1016/j.cell.2008.11.020

Saleem M, Morlot S, Hohendahl A, Manzi J, Lenz M, Roux A (2015) A balance between membrane elasticity and polymerization energy sets the shape of spherical clathrin coats. Nat Commun 6:6249. https://doi.org/10.1038/ncomms7249

Saliba A-E, Vonkova I, Deghou S, Ceschia S, Tischer C, Kugler KG, Bork P, Ellenberg J, Gavin A-C (2016) A protocol for the systematic and quantitative measurement of protein-lipid interactions using the liposomemicroarray-based assay. Nat Protoc 11:1021-1038. https://doi.org/10.1038/nprot.2016.059

Schmid EM, McMahon HT (2007) Integrating molecular and network biology to decode endocytosis. Nature 448:883-888. https://doi.org/10.1038/nature06031

Schmidt TG, Skerra A (2007) The Strep-tag system for one-step purification and high-affinity detection or capturing of proteins. Nat Protoc 2:1528-1535. https://doi.org/10.1038/nprot.2007.209

Schumacher S, Nunez RV, Biertümpfel C, Mizuno N (2021) Bottom-up reconstitution of focal adhesion complexes. FEBS J. https://doi.org/10.1111/febs.16023

Senju Y, Lappalainen P, Zhao H (2021) Phosphoinositides, Methods and Protocols. Methods Mol Biol 2251:195204. https://doi.org/10.1007/978-1-0716-1142-5_14

Shaw ML, Stone KL, Colangelo CM, Gulcicek EE, Palese P (2008) Cellular proteins in influenza virus particles. PLOS Pathog 4:e1000085. https://doi.org/10.1371/journal.ppat.1000085 
bioRxiv preprint doi: https://doi org/10.1101/2021.12.06.471516; this version posted December 7, 2021. The copyright holder for this

preprint (which was not certified by peer review) is the author/funder, who has granted bioRxiv a license to display the preprint in perpetuity. It is made available under aCC-BY-NC-ND 4.0 International license.

Traub LM (2005) Common principles in clathrin-mediated sorting at the Golgi and the plasma membrane

Biochim Biophys Acta (BBA) - Mol Cell Res 1744:415-437. https://doi.org/10.1016/j.bbamcr.2005.04.005

Traub LM (2009) Tickets to ride: selecting cargo for clathrin-regulated internalization. Nat Rev Mol Cell Biol 10:583-596. https://doi.org/10.1038/nrm2751

Wu M, Huang B, Graham M, Raimondi A, Heuser JE, Zhuang X, Camilli PD (2010) Coupling between clathrindependent endocytic budding and F-BAR-dependent tubulation in a cell-free system. Nat Cell Biol 12:902908. https://doi.org/10.1038/ncb2094

Zhao H, Lappalainen P (2012) A simple guide to biochemical approaches for analyzing protein-lipid interactions. Mol Biol Cell 23:2823-2830. https://doi.org/10.1091/mbc.e11-07-0645 